\title{
Do we understand urinary retention in women? Current understanding and future perspectives: ICI-RS 2017
}

\section{Running title: Urinary retention in women}

Jalesh N. Panicker ${ }^{1}$, Ralf Anding ${ }^{2}$, Salvador Arlandis ${ }^{3}$, Bertil Blok ${ }^{4}$, Caroline Dorrepaal ${ }^{5}$, Chris Harding ${ }^{6}$, Tom Marcelissen ${ }^{7}$, Kevin Rademakers ${ }^{7}$, Paul Abrams ${ }^{8}$, Apostolos Apostolidis $^{9}$

${ }^{1}$ Department of Uro-Neurology, The National Hospital for Neurology and Neurosurgery and UCL Institute of Neurology, Queen Square, London, United Kingdom

${ }^{2}$ Neurourology, Department of Urology and Pediatric Urology, University Hospital Bonn, Bonn, Germany.

${ }^{3}$ Department of Urology, Hospital Universitario y Politécnico La Fe, Valencia, Spain

${ }^{4}$ Department of Urology, Erasmus Medical Center, Rotterdam, The Netherlands

${ }^{5}$ Astellas Pharma Europe B.V., Leiden, The Netherlands

${ }^{6}$ Department of Urology, Freeman Hospital, Newcastle Upon-Tyne, United Kingdom

${ }^{7}$ Department of Urology, Maastricht University Medical Centre, Maastricht, The Netherlands

${ }^{8}$ Professor of Urology, University of Bristol

Head of Teaching and Research, Bristol Urological Institute

Chair, International Consultation on Urological Diseases

${ }^{9} 2^{\text {nd }}$ Department of Urology, Aristotle University of Thessaloniki, Thessaloniki, Greece 


\section{Abstract}

\section{Aims}

Urinary retention in women is poorly understood, compared to the equivalent condition in men, and was the subject of a dedicated session organised at the International Consultation on Incontinence Research Society (ICI-RS) in Bristol, United Kingdom, 2017.

\section{Methods}

The current understanding of the pathophysiological correlates of idiopathic voiding dysfunction in women, the role of urodynamics, neurophysiology, and non-invasive tests in characterising functional bladder outlet obstruction due to a non-relaxing urethral sphincter, and poorly defined diagnosis of detrusor underactivity were reviewed.

\section{Results}

Putative factors underlying the pathogenesis of urinary retention following urinary tract infections were discussed. Further research is required to explore the association between bladder wall inflammation and alterations in detrusor contractile functions. The complex interrelationship between urinary retention and psychological co-morbidities and sexual trauma were explored, and the overlap between these and psychological comorbidities and functional neurological problems with functional urological problems were recognised. Understanding the mechanism of action of sacral neuromodulation, often a successful treatment for urinary retention, would provide insight into the underlying factors that may be responsible for urinary retention. Specifically, there is a 
need to understand the role of the endogenous enkephalinergic system in the pathogenesis of urinary retention and to identify predictors of successful treatment with sacral neuromodulation. Based on current understanding and potential directions of research in the future, an algorithm for the evaluation of women with voiding dysfunction was proposed.

\section{Conclusions}

In the future, recommendations for research should lead to a better understanding of urinary retention in women and its treatment.

Key words: voiding dysfunction, Fowler's syndrome, dysfunctional voiding, opiates, psychological co-morbidities, sexual abuse, sacral neuromodulation, urinary tract infections 


\section{Introduction}

Urinary retention is not an uncommon problem in women, but to date this condition has been poorly studied ${ }^{1-3}$. In the EpiLUTS study, a sensation of incomplete bladder emptying was reported by $27.4 \%$ and a weak flow by $20 \%$ of women aged $>40$ years 4 . Urodynamic and imaging studies help to delineate the pathophysiological correlates to urinary retention such as bladder outlet obstruction (BOO, reported in $2-23 \%)^{1}$ or detrusor underactivity (DU, reported in $12-45 \%$ of older women) ${ }^{5}$ ) in women investigated for lower urinary tract (LUT) symptoms. The lack of accurate definitions and appropriate diagnosis for either condition may be largely responsible for the apparent epidemiological discrepancies, but also reflect the lack of studies of female urinary retention to date.

\section{Methods}

At the International Consultation on Incontinence Research Society (ICI-RS) in Bristol, United Kingdom, 2017, a panel of clinicians and scientists participated in a think-tank discussing female voiding difficulty / urinary retention. The aim was to identify current problems with the diagnosis and treatment of female urinary retention and to produce a consensus view within this subject area in the form of a proposed algorithm to encourage a consistent approach for these patients.

The panellists reviewed the literature regarding the pathophysiology of voiding dysfunction in women, different triggering factors for urinary retention, diagnostic potential of invasive (urodynamics, neurophysiology) and non-invasive (imaging) tests 
and the current understanding of the mechanisms by which sacral neuromodulation works. From the discussions at the meeting and subsequent e-mail iterations, the panel proposed priority areas of further research to advance the current understanding as well as an algorithm for the evaluation of female voiding dysfunction.

\section{Voiding dysfunction in women}

Voiding dysfunction in this document implies abnormally slow, intermittent micturition and/or incomplete bladder emptying, and is a diagnosis that is made following the

recording of symptoms and analysis of urodynamic investigations ${ }^{6}$. There are a few established causes for voiding dysfunction in women (table 1).

Voiding dysfunction is rather heterogeneous in women, and urodynamic studies are considered mandatory in order to provide useful information regarding the alterations in LUT function contributing to voiding dysfunction such as detrusor underactivity (DU) and bladder outlet obstruction (BOO).

\section{Bladder outlet obstruction in women}

The characteristic findings of bladder outlet obstruction (BOO) are an increased detrusor pressure, reduced urine flow rate and often the presence of a raised post-void residual $(\mathrm{PVR})^{6}$. $\mathrm{BOO}$ is relatively uncommon in women, and there are a few structural and functional causes (Table 1). In the 1980s, Fowler et al. described a cohort of young women presenting in complete urinary retention with the finding of a specific electromyographic (EMG) pattern recorded from the striated urethral sphincter, 
characterised by complex repetitive discharges (CRDs) and decorating bursts (DBs), and often with accompanying clinical features of polycystic ovaries ${ }^{7}$. The syndrome has since become known as Fowler's syndrome (FS) and routine cystometry may not always demonstrate $\mathrm{BOO}$, but rather a large capacity bladder without the usual sensations during the filling phase. The maximum urethral closure pressure (MUCP) is found to be elevated, with values typically above $100 \mathrm{~cm} \mathrm{H}_{2} \mathrm{O}$ and the urethral sphincter volume often enlarged in transvaginal ultrasonography. It is thought that the abnormal EMG activity prevents relaxation of the striated sphincter and abnormally high urethral pressure, and, through an exaggerated pro-continence guarding response, poor bladder sensations and contractile function ${ }^{8}$. CRDs have been reported from other pelvic floor muscles in women presenting with isolated urinary retention ${ }^{9}$, and in apparently asymptomatic women ${ }^{10,11}$ and therefore the association between the abnormal EMG signal and voiding dysfunction requires further exploration. Recently, EMG abnormalities have been shown to be associated with a pulsatile pattern in the UPP, and the underlying pathophysiological basis for this observation requires further study 12.

\section{Detrusor underactivity}

Detrusor underactivity (DU) is common, especially in elderly women, with a prevalence of up to $45 \%{ }^{5}$. Defined as "a contraction of reduced strength and/or duration, resulting in prolonged bladder emptying and/or failure to achieve complete bladder emptying within a normal time span", there has been an increased interest in the clinical characteristics of DU, to diagnose the condition ${ }^{13}{ }^{14}$. The common causes for DU in women are listed in Table 1. 
There is a need to further understand the pathophysiological correlates to voiding dysfunction and longitudinal studies are needed to answer some of the unanswered questions:

- Do the clinical features, natural history and treatment outcomes differ between women with functional $\mathrm{BOO}$ and $\mathrm{DU}$ ?

- Does the clinical profile of women with voiding dysfunction due to a primary disorder of urethral sphincter relaxation differ from women with non-relaxing pelvic floor, where biofeedback is an effective treatment?

- What is the contribution of the smooth muscle present at the bladder outlet to the development of obstructed voiding in women with evidence of a non-relaxing urethral sphincter?

- What is the role of the endogenous enkephalinergic system in the pathogenesis of urinary retention in women with a primary disorder of urethral sphincter relaxation?

\section{Assessment}

Figure 1 provides an overview of the assessment of women presenting in urinary retention ${ }^{15}$. The ability to predict whether voiding dysfunction is due to $\mathrm{BOO}$ or DU based on symptoms alone is low ${ }^{13}$. Voiding symptoms are common in both, and while storage symptoms commonly co-exist in patients with DU due to voiding in low urine volumes, the finding of detrusor overactivity (DO) is common in older patients with DU 5 . In women with dysfunctional voiding, characterized by an intermittent and/or fluctuating 
flow rate due to involuntary intermittent contractions of the peri-urethral striated or levator muscles during voiding in neurologically normal women ${ }^{6}$, storage symptoms were twice as prevalent as voiding symptoms $(67.9 \%$ vs. $32.1 \%)$ in women with dysfunctional voiding, urinary frequency being the most common complaint $(41 \%)$, followed by dysuria (32.1\%) and urgency incontinence $(15.5 \%)^{16}$. The presence of a high PVR alone is also non-diagnostic with low sensitivity (13-57\%) and specificity (18$38 \%)^{3}$. Women with $\mathrm{BOO}$ due to a poorly relaxing urethral sphincter from FS are typically young and have attained menarche. Residual volumes are often demonstrated to exceed 1 litre at some stage and although they may experience pain, they do not report the expected urgency at such a large bladder capacity. Straining does not help emptying, and performing intermittent self-catheterisation is often painful, particularly on removal of the catheter, with many women complaining of a sensation of "something gripping" as the catheter is withdrawn ${ }^{17}$.

Attempts have been made to recognise symptoms that may distinguish BOO from DU and an older age, enuresis, stress incontinence and impaired sensations of bladder fullness may occur more frequently in DU, whereas a "gripping sensation" during attempted catheter removal is characteristically described in functional BOO especially due to Fowler's syndrome ${ }^{13} 17$ 14. Preliminary results from a cohort of women with voiding symptoms present in 75\% suggested a lower Qmax and higher bladder voiding efficiency upon free-flow to be more predictive of $\mathrm{BOO}{ }^{18}$.

\section{Non-invasive Urodynamics}


The predictive value of uroflowmetry for the diagnosis of $\mathrm{BOO}$ and $\mathrm{DU}$ has been investigated in an effort to standardize diagnostic criteria. Voiding dysfunction has been defined as a urine flow below the 10th maximum flow rate centile of the Liverpool nomograms, or as a maximum flow of $\leq 15 \mathrm{~mL} / \mathrm{s}$ and/or a PVR $\geq 50 \mathrm{~mL}$. A crosssectional multicentre study of women with pelvic organ prolapse aged $>55$ years reported $39.7 \%$ with voiding symptoms, and using the above mentioned cut-off, it was demonstrated that the nomograms may be more predictive of voiding dysfunction than the combination of uroflow parameters and PVR ${ }^{19}$. These results conflicted with an earlier study, which reported the odds of diagnosing voiding difficulty as $3.7(95 \% \mathrm{Cl}$, 1.9-7) using uroflowmetry compared to $2.8(95 \% \mathrm{Cl}, 1.6-5.2)$ using the Liverpool nomogram. Uroflowmetry was found to have a specificity of $>70 \%$ but with a wide range of sensitivities (50-100\%) depending on the cut-offs chosen ${ }^{20}$.

\section{Invasive urodynamics}

The role of cystometry in the evaluation of urinary retention in women is not well defined. Most studies have focussed on the urodynamic diagnosis of BOO with various criteria proposed which are based on voiding pressure, urine flow rate and fluoroscopic appearances. These are summarised in Table 2212223242526 .

No consensus exists on which of these criteria are most accurate and a "gold standard" is yet to be established.

Fluoroscopy in combination with cystometry can be invaluable in certain circumstances for instance primary bladder neck obstruction, urethral stricture and extrinsic outlet 
compression. Consequently, most clinicians would routinely advocate theuse of video urodynamics.

\section{Urethral Pressure Profilometry (UPP)}

The UPP can be helpful in delineating the cause of female urethral retention and is of particular relevance when the pressure-flow measurements and radiological appearances suggest a large maximum cystometric capacity and impaired ability to mount detrusor pressures. These are findings that are common for both DU ${ }^{27}$ and Fowler's Syndrome ${ }^{28}$, however the finding of a high maximal urethral closure pressure would suggest the latter ${ }^{8}$.

\section{Cystoscopy}

Cystoscopy is useful to assess the bladder outlet and exclude anatomical causes for obstruction, as well as to identify structural bladder alterations or complications of BOO such as trabeculations, diverticula and dilated ureteric orifices which may suggest vesico-ureteric reflux. Cystoscopy is routinely performed in the investigation of women presenting with voiding difficulties, however the usefulness of this test needs to be researched.

\section{Pelvic Neurophysiology}

Concentric needle electromyography (EMG) of the striated urethral sphincter may reveal abnormal signals in women presenting with urinary retention due to BOO. Over the audio-amplifier of the EMG machine, complex repetitive discharges (CRDs) produce 
a sound similar to helicopter sounds, and the decelerating component of a CRD, known as decelerating bursts (DB), produce a characteristic sound akin to the sound of underwater recording of whale songs ${ }^{29}$. Other pelvic neurophysiology tests recording the anal sphincter EMG, bulbocavernosus reflex and pudendal sensory evoked potentials assess the integrity of the somatic S2,3,4 nerve roots. These tests however are performed only at specialist centres and are indicated particularly in situations where an obscure lesion of the sacral roots or conus medullaris is suspected to be the cause for retention, though their clinical utility needs to be better defined.

\section{Emerging non-invasive tests}

Magnetic resonance imaging (MRI) of the pelvic floor allows for precise evaluation of ligaments, muscles, and pelvic organs and provides accurate information about the three compartments of the pelvic floor ${ }^{30,31}$. However, these techniques are mostly used diagnostically in conditions of a 'weak' pelvic floor: cystoceles, rectoceles, enteroceles, fascia damage, ligament damage, bowel dysfunction. The high resolution of images, the ability to acquire dynamic sequences during voiding, and the lack of radiation makes MRI an attractive tool to study functional disorders of the pelvic floor. Moreover, MRI may have applications in the evaluation of functional BOO, as an enlarged urethral sphincter is seen in women with FS ${ }^{8}$. Dynamic MRI studies during the voiding phase may help to study pelvic floor descent and identify differences in bladder and bowel configuration during straining. These studies may be combined with simultaneous urodynamic recordings, however is not available for routine clinical use at present. 
Ultrasonography of the pelvic floor has emerged as a non-invasive technique to examine the pelvic floor in women with incontinence and pelvic organ prolapse (POP). 2-D, 3-D and 4-D techniques with application of the probe translabially $3233-3536$, transabdominally ${ }^{37}$ and transvaginally have been evaluated ${ }^{30}$. Results are conflicting, however, and despite the known association between levator ani abnormalities and an underactive pelvic floor, no relation to incontinence or POP was identified ${ }^{38}$. Contradictory findings have also been reported in studies evaluating bladder wall thickness (BWT) ultrasonographically in patients with functional LUT disorders ${ }^{39,40}$. Transabdominal measurement of BWT was found to correlate with both $\mathrm{BOO}$ and DU in a series of 167 women with LUTS ${ }^{40}$, whereas in a larger cohort of women, detrusor wall thickness in symptomatic women was no different from asymptomatic women, and was not associated with parameters of voiding function, or urodynamic indices of $\mathrm{BOO}{ }^{39}$. Promising novel techniques for the future include dynamic ultrasonography performed during voiding, and shear wave elastography (which aims to provide a quantitative assessment of bladder neck elasticity) ${ }^{41}$, however findings have not been correlated with voiding symptoms or urodynamic findings.

Other exploratory non-invasive tests include measurement of urinary nerve growth factor (NGF) levels ${ }^{42}$, surface EMG of the pelvic floor ${ }^{43}$ and cardiovascular testing for occult dysautonomia ${ }^{44}$. To date there have been no studies showing correlation of these techniques with symptoms or urodynamic findings. 
The results from tests provide some insight into the LUT dysfunction, however to what extent they contribute to our understanding of female voiding dysfunction has been poorly researched and there are several unanswered questions:

- Are the currently established tests- (video)cystometry and urethral pressure profile (UPP)- sufficient to characterise the LUT dysfunction responsible for urinary retention in women? Which women with voiding dysfunction should have UPP measurements?

- What is the role of pelvic neurophysiology testing in the evaluation of women presenting with voiding dysfunction?

- How do the findings of abnormal EMG signals in the urethral sphincter (decelerating bursts and complex repetitive discharges) correlate with the clinical and urodynamic findings of Fowler's syndrome (FS)?

- Can the presence of abnormal EMG signals in otherwise asymptomatic women serve as a marker of susceptibility for developing urinary retention at a later stage?

- What is the role for non-invasive tests such as sphincter imaging (ultrasound, routine $\mathrm{MRI}$ ), dynamic MRI and urinary biomarkers (eg. NGF) in the evaluation of urethral sphincter and pelvic floor functions in women presenting with bladder outlet obstruction?

- Is there evidence for more generalised autonomic dysfunction (eg. cardiovascular, sweat, pupillary abnormalities) in women presenting with idiopathic urinary retention? 
- Are there techniques to evaluate the afferent signalling pathway from the urethra of women and its role in the pathogenesis of "detrusor failure"?

- What are the predictive associations between non-invasive urodynamics with invasive pressure-flow urodynamic studies?

- Can a multicentre study be designed to develop and test an acceptable diagnostic index for female bladder outlet obstruction?

\section{Factors known to be associated with urinary retention in women}

Different triggering factors and co-morbidities seem to be associated with retention.

\section{Urinary tract infections}

Urinary tract infections (UTI) are often reported as a triggering factor for retention in women. The basis for this is uncertain but a link between inflammatory changes and the development of DU involving the 'mechanosensitive transducer' comprising urothelium, interstitial cells, detrusor and ganglia of the bladder has been postulated. During inflammation, different mediators of the 'mechanosensitive transducer' are altered such as elevation of TNF- $\alpha$, suppression of NGF and lower expression of Ecadherin. Together with oxidative stress, altered expression of receptors (lower expression of $\mathrm{M}_{2-}, \mathrm{M}_{3}-, \mathrm{P}_{2} \mathrm{X}_{3}$-receptors; higher expression of $\mathrm{B}_{3}$-receptors), and activation of different cells-types (increased mast cells, macrophages and apoptotic cells in the suburothelial layer) may significantly influence afferent activity from the bladder 4546 . The role of afferent signalling in modulating the strength, velocity, and duration of detrusor contraction is now being recognised ${ }^{47}$ in type 2 diabetes mellitus 
(DM), where age and recurrent urinary tract infections were identified as independent factors for developing impaired voiding function ${ }^{48}$.

Changes in detrusor contractile strength follow a dynamic course ${ }^{49}$, exhibiting a possible biphasic response in some, with initial changes of overactivity, followed by sequelae such as DU. The evidence so far in diabetic patients and the elderly suggest that both histological changes of the detrusor muscle, as well as the cascade of inflammatory reactions, may have a major contribution to the development of DU.

\section{Opiate use}

Opiates exert a suppressor effect on LUT function through spinal $\mu$ - and $\partial$-opioid receptors that induce bladder relaxation by activating descending inhibitory systems, as well as possibly through direct effects ${ }^{50}$. Furthermore, opiates peripherally impair the perception of bladder sensation of fullness by inhibiting the parasympathetic outflow and increasing the (internal) sphincter tone by sympathetic over-stimulation, resulting in increased bladder outlet resistance ${ }^{51}$. Epidurally administered morphine has been shown to be associated with marked relaxation of the detrusor in simultaneously performed urodynamic studies and was associated with an increase in maximal bladder capacity and urinary retention ${ }^{52}$. Studies have demonstrated a much stronger inhibitory effect on bladder function following spinal administration of opiates, compared to intraventricular, intravenous or intramuscular routes ${ }^{53}$. A meta-analysis of 94 studies with pooled data of 12,513 patients showed that the highest retention rate (mean $29.1 \%$ ) occurred with epidural analgesia, strengthening the association between postoperative pain management and the risk of urinary retention ${ }^{54}$. A double-blind 
study evaluating the urodynamic effects of $\mu$-agonists (fentanyl, morphine) and partial $\mu$ agonist-antagonist (buprenorphine) showed that the administration of fentanyl and buprenorphine resulted in altered bladder sensations, increased PVRs and reduced detrusor contractions in men. Compliance and urethral pressures did not change ${ }^{55}$. The effects in women however are uncertain. Tramadol was reported to cause transient impairment of voiding, which resolved after stopping the drug ${ }^{56}$. There is also evidence that orally administered opiates play a role in developing urinary retention in women, often in the context of Fowler's syndrome. It is hypothesized that Fowler's syndrome is due to an up-regulation of spinal cord enkephalins, and that exogenous opiates may compound functional abnormalities and thereby predisposing young women to urinary retention ${ }^{57}$.

\section{Psychological co-morbidities and sexual abuse}

The relatively high prevalence of psychological co-morbidities observed in women with urinary retention raises questions around the association between psychological and sexual trauma and LUT dysfunction. A retrospective chart review of 61 women with FS suggested that $24 \%$ reported medically unexplained/"functional" symptoms, including loss of consciousness, limb weakness, sensory disturbance and memory impairment. Furthermore, almost a third (31\%) had psychological co-morbidities such as anxiety/depression or obsessive compulsive symptoms ${ }^{58}$. Furthermore, several questionnaire-based studies have demonstrated an association with depression requiring hospitalisation, hysteria, depression, risk of somatisation, definitive somatoform disorder and unspecified psychiatric disorders 59606162 . However despite 
the evidence to suggest increase rates of psychological co-morbidities in this group, the impact of these co-morbidities on treatment outcomes has yet to be elucidated.

Sexual abuse can result in psychological trauma, but also pelvic floor damage. A higher prevalence of abuse is reported amongst women with psychological co-morbidities, as well as with LUT dysfunction, however the nature of these associations is poorly understood. Prevalence figures of abuse amongst women in a western population is considerable, ranging between $12 \%$ to $25 \% 6364$. A community based survey found a strong correlation between abuse and symptoms of voiding dysfunction, such as urinary frequency, urgency and nocturia ${ }^{65} .20 \%$ of a large cohort of children reporting a history of sexual abuse complained of one or more urogenital symptoms ${ }^{66}$. In a smaller study, $72 \%$ of individuals with a history of sexual abuse reported voiding dysfunction, compared to $22 \%$ of controls ${ }^{67}$. In addition, $23 \%$ of patients attending a pelvic floor center reported a history of abuse. Patients with multiple urogenital complaints were more likely to have a history of abuse than patients with isolated complaints ${ }^{68}$. Whether addressing psychological trauma related to sexual abuse helps to ameliorate voiding symptoms requires further study.

The association between triggering factors and the pathogenesis of urinary retention needs further exploring:

- How does the inflammatory response in the bladder wall triggered by a UTI influence detrusor contractile functions? 
- Which are the opiate receptor sub-types involved in the central inhibition of LUT functions following exogenously administered opiates?

- Are there any phenotypic/genetic characteristics which can help to prognosticate the risk for developing urinary retention following exposure to prescription opiates?

- What is the role of the enkephalinergic system in the midbrain and other regions of the brain stem in the pathogenesis of urinary retention following exposure to opiates?

- Do exogenous opiates influence lower urinary tract functions peripherally- at the level of ganglia in the pelvic splanchnic nerves or directly through receptors in the urothelium, suburothelium or detrusor?

- What are the different types of functional disorders/ psychological co-morbidities seen in women with urinary retention?

- How does the profile of functional symptoms/ psychological co-morbidities differ between women with urinary retention and women with other types of lower urinary tract symptoms, ie. predominantly overactive bladder

- What is the nature of the association between lower urinary tract dysfunction and medically unexplained symptoms in women with idiopathic urinary retention or with Fowler's syndrome?

- Is there a role for psychological assessment when selecting women in urinary retention for sacral neuromodulation?

- Is there a role of managing concomitant psychological co-morbidities using psychological treatments (eg. cognitive behavioural therapy (CBT), systematic 
desensitisation, biofeedback) for women in retention for whom sacral neuromodulation is being planned? What effects do these psychological treatments have on voiding dysfunction?

- How does the management of urinary retention fit within the biopsychosocial model of managing medically unexplained functional disorders?

\section{Sacral Neuromodulation}

Sacral neuromodulation (SNM) is a well-established successful treatment for idiopathic urinary retention in women, and may serve as a tool to understand the cause for voiding dysfunction. An exaggerated pro-continence guarding response is thought to inhibit bladder afferent and efferent activity in FS and SNM may work by restoring functions via these signalling pathways ${ }^{69}$. A functional MRI study in women with FS suggested alterations of activation in different regions of the brain, and these changes were reversed when the stimulator was switched on ${ }^{70}$. Bladder filling was shown to elicit abnormally strong urethral afferent signals that inhibit bladder afferent activity in the sacral cord, preventing input to the periaqueductal grey and higher brain centres. Thus, SNM seems to act at the level of the sacral cord, by modulating urethral afferents. Recent evidence suggests that modulating the enkephalinergic system plays a role in inhibition of bladder overactivity during SNM ${ }^{71}$.

In patients with DU, SNM may target bladder contractile function rather than the bladder outlet. Bladder contractility significantly improved following SNM in a cohort with 
detrusor underactivity who had "detrusor hypocontractility" on urodynamics ${ }^{72}$. In a cohort of patients with detrusor overactivity with impaired contractility (DHIC), a typical condition in the elderly, $70 \%$ undergoing test stimulation showed a treatment response and both DO during filling and DU during voiding improved ${ }^{73}$.

Not all women with idiopathic retention respond to SNM however, and recognizing prognostic factors may highlight underlying mechanisms responsible for developing retention. Women with $\mathrm{BOO}$ due to FS have a longer duration of benefit, as well as lower revision rates ${ }^{61}$. Better outcomes have been shown in patients with urinary retention who are able to void at least more than $50 \mathrm{~mL}{ }^{74}$, whereas patients with worse detrusor function assessed using the Maastricht-Hannover nomogram were found less likely to respond to SNM ${ }^{72}$. The finding of acontractility at ambulatory urodynamics is also associated with poor outcomes ${ }^{75}$. A recent review of 356 patients found no relationship between age and treatment success and suggested that age reduces the need for surgical revision by $3 \%$ per additional year of age ${ }^{76}$.

A history of mental health problems such as hysteria, depression and hypochondria has been shown to be associated with shorter duration of effect 775978,62 , and furthermore, higher revision rates have been observed in patients prescribed antidepressants and analgesics ${ }^{79}$. Conversely, no association was found between an abnormal Hospital Anxiety and Depression Score and efficacy or safety outcomes following SNM ${ }^{80}$.

Very little is known regarding sacral neuromodulation and its mechanism of action in urinary retention: 
- What role do endogenous endorphins play in the effects of sacral neuromodulation?

- What are the factors that influence outcomes following SNM in women with urinary retention?

- Does the pattern of LUT dysfunction (ie. detrusor underactivity or bladder outlet obstruction), degree of detrusor underactivity (urodynamic findings of underactivity versus acontractility) or concomitant use of opiates influence outcomes following SNM?

\section{Future direction}

On the basis of our current understanding, and potential future directions of research, an algorithm to evaluate the cause for voiding dysfunction in women is proposed (figure 1). Currently available investigations recognise a cause in only a proportion of cases, and in the rest the cause remains "idiopathic". There is a need to further understand the pathophysiological correlates to voiding dysfunction and whereas urodynamic testing provides some information, emerging non-invasive tests, and neurophysiology, may provide further insight into the causes and expand our understanding, and our ability to effectively treat voiding dysfunction in women. It is possible that there exists a cohort of women with a susceptibility to develop urinary retention based upon a putative phenotypic (such as an abnormal urethral sphincter EMG) and genetic characteristics. Further research is required to identify these factors so that in the future it may be possible to define this susceptibility and develop a "scoring system" of different factors 
to define risk. Urinary retention may then manifest only in those with the greatest score (susceptibility) when exposed to different triggering factors. Moreover, understanding how these different triggers can precipitate urinary retention opens new directions for treatment. The role of the endogenous enkephalinergic system in the pathogenesis of urinary retention is of particular interest as it may emerge as target for new treatments. Sacral neuromodulation responses may also allow for a better understanding of the causes of voiding dysfunction. 


\section{Acknowledgments}

JNP undertook this work at UCLH/UCL Institute of Neurology and is supported in part by funding from the United Kingdom's Department of Health NIHR Biomedical Research Centres funding scheme. 
Figures

Figure 1. Proposed clinical approach to women presenting with voiding difficulties 


\section{References}

1. Groutz A, Blaivas JG. Non-neurogenic female voiding dysfunction. Curr Opin Urol 2002;12(4):311-316.

2. van Koeveringe GA, Vahabi B, Andersson KE, Kirschner-Herrmans R, Oelke M. Detrusor underactivity: a plea for new approaches to a common bladder dysfunction. Neurourol Urodyn 2011;30(5):723-728.

3. Abdel Raheem A, Madersbacher H. Voiding dysfunction in women: How to manage it correctly. Arab J Urol 2013;11(4):319-330.

4. Coyne KS, Sexton CC, Thompson CL, et al. The prevalence of lower urinary tract symptoms (LUTS) in the USA, the UK and Sweden: results from the Epidemiology of LUTS (EpiLUTS) study. BJU Int 2009;104(3):352-360.

5. Osman NI, Chapple CR, Abrams $\mathrm{P}$, et al. Detrusor underactivity and the underactive bladder: a new clinical entity? A review of current terminology, definitions, epidemiology, aetiology, and diagnosis. Eur Urol 2014;65(2):389-398.

6. Haylen BT, de Ridder D, Freeman RM, et al. An International Urogynecological Association (IUGA)/International Continence Society (ICS) joint report on the terminology for female pelvic floor dysfunction. Neurourol Urodyn 2010;29(1):4-20.

7. Fowler CJ, Christmas TJ, Chapple CR, Parkhouse HF, Kirby RS, Jacobs HS. Abnormal electromyographic activity of the urethral sphincter, voiding dysfunction, and polycystic ovaries: a new syndrome? BMJ 1988;297(6661):1436-1438.

8. Wiseman OJ, Swinn MJ, Brady CM, Fowler CJ. Maximum urethral closure pressure and sphincter volume in women with urinary retention. J Urol 2002;167(3):1348-1351; discussion 1351-1342.

9. Webb RJ, Fawcett PR, Neal DE. Electromyographic abnormalities in the urethral and anal sphincters of women with idiopathic retention of urine. Br J Urol 1992;70(1):22-25.

10. Ramm O, Mueller ER, Brubaker L, Lowenstein L, Kenton K. Complex repetitive discharges--a feature of the urethral continence mechanism or a pathological finding? J Urol 2012;187(6):2140-2143.

11. Tawadros C, Burnett K, Derbyshire LF, Tawadros T, Clarke NW, Betts CD. External urethral sphincter electromyography in asymptomatic women and the influence of the menstrual cycle. BJU Int 2015;116(3):423-431.

12. Sihra N, Malde S, Panicker J, et al. Does the appearance of the urethral pressure profile trace correlate with the sphincter EMG findings in women with voiding dysfunction? Neurourol Urodyn 2017.

13. Gammie A, Kaper M, Dorrepaal C, Kos T, Abrams P. Signs and Symptoms of Detrusor Underactivity: An Analysis of Clinical Presentation and Urodynamic Tests From a Large Group of Patients Undergoing Pressure Flow Studies. Eur Urol 2016;69(2):361-369.

14. Rademakers K, Oelke M, van Koeveringe G. Detrusor underactivity in women: Significant correlation between standardised medical history assessment and urodynamic findings. Neurourol Urodyn 2014;33:922.

15. Panicker JN, Fowler CJ, Kessler TM. Lower urinary tract dysfunction in the neurological patient: clinical assessment and management. Lancet Neurol 2015;14(7):720-732.

16. Chen YC, Kuo HC. Clinical and video urodynamic characteristics of adult women with dysfunctional voiding. J Formos Med Assoc 2014;113(3):161-165. 
17. Swinn MJ, Wiseman OJ, Lowe E, Fowler CJ. The cause and natural history of isolated urinary retention in young women. J Urol 2002;167(1):151-156.

18. Mytilekas K, Oeconomou A, Sokolakis I, et al. Can we predict a diagnosis of detrusor underactivity or bladder outlet obstruction in women by non-invasive parameters? Abstract \#370, ICS 2017.

19. Casteleijn NF, Panman CM, Wiegersma M, Kollen BJ, Messelink EJ, Dekker JH. Free uroflowmetry for voiding dysfunction measurement in women with pelvic organ prolapse and urinary incontinence in primary care. Int J Urol 2015;22(8):801-802.

20. Costantini E, Mearini E, Pajoncini C, Biscotto S, Bini V, Porena M. Uroflowmetry in female voiding disturbances. Neurourol Urodyn 2003;22(6):569-573.

21. Farrar DJ, Osborne JL, Stephenson TP, et al. A urodynamic view of bladder outflow obstruction in the female: factors influencing the results of treatment. Br J Urol 1975;47(7):815-822.

22. Massey JA, Abrams PH. Obstructed voiding in the female. Br J Urol 1988;61(1):36-39.

23. Chassagne S, Bernier PA, Haab F, Roehrborn CG, Reisch JS, Zimmern PE. Proposed cutoff values to define bladder outlet obstruction in women. Urology 1998;51(3):408-411.

24. Nitti VW, Tu LM, Gitlin J. Diagnosing bladder outlet obstruction in women. J Urol 1999;161(5):1535-1540.

25. Blaivas JG, Groutz A. Bladder outlet obstruction nomogram for women with lower urinary tract symptomatology. Neurourol Urodyn 2000;19(5):553-564.

26. Defreitas GA, Zimmern PE, Lemack GE, Shariat SF. Refining diagnosis of anatomic female bladder outlet obstruction: comparison of pressure-flow study parameters in clinically obstructed women with those of normal controls. Urology 2004;64(4):675-679; discussion 679-681.

27. Abrams P, Cardozo L, Fall M, et al. The standardisation of terminology of lower urinary tract function: report from the Standardisation Sub-committee of the International Continence Society. Neurourol Urodyn 2002;21(2):167-178.

28. DasGupta R, Fowler CJ. Urodynamic study of women in urinary retention treated with sacral neuromodulation. J Urol 2004;171(3):1161-1164.

29. Fowler CJ, Kirby RS, Harrison MJ. Decelerating burst and complex repetitive discharges in the striated muscle of the urethral sphincter, associated with urinary retention in women. J Neurol Neurosurg Psychiatry 1985;48(10):1004-1009.

30. Garcia del Salto L, de Miguel Criado J, Aguilera del Hoyo LF, et al. MR imaging-based assessment of the female pelvic floor. Radiographics 2014;34(5):1417-1439.

31. Yang A, Mostwin JL, Rosenshein NB, Zerhouni EA. Pelvic floor descent in women: dynamic evaluation with fast MR imaging and cinematic display. Radiology 1991;179(1):25-33.

32. Kruger JA, Heap SW, Murphy BA, Dietz HP. Pelvic floor function in nulliparous women using three-dimensional ultrasound and magnetic resonance imaging. Obstet Gynecol 2008;111(3):631-638.

33. Dietz HP, Kirby A, Shek KL, Bedwell PJ. Does avulsion of the puborectalis muscle affect bladder function? Int Urogynecol J Pelvic Floor Dysfunct 2009;20(8):967-972.

34. Lovegrove Jones RC, Peng Q, Stokes M, Humphrey VF, Payne C, Constantinou CE. Mechanisms of pelvic floor muscle function and the effect on the urethra during a cough. Eur Urol 2010;57(6):1101-1110.

35. Falkert A, Endress E, Weigl M, Seelbach-Gobel B. Three-dimensional ultrasound of the pelvic floor 2 days after first delivery: influence of constitutional and obstetric factors. Ultrasound Obstet Gynecol 2010;35(5):583-588.

36. Notten KJ, Weemhoff M, Kluivers KB, et al. Protocol for translabial 3D-ultrasonography for diagnosing levator defects (TRUDIL): a multicentre cohort study for estimating the diagnostic 
accuracy of translabial 3D-ultrasonography of the pelvic floor as compared to MR imaging. BMC Womens Health 2011;11:23.

37. Bo K, Sherburn M, Allen T. Transabdominal ultrasound measurement of pelvic floor muscle activity when activated directly or via a transversus abdominis muscle contraction. Neurourol Urodyn 2003;22(6):582-588.

38. Steensma AB, Konstantinovic ML, Burger CW, de Ridder D, Timmerman D, Deprest J. Prevalence of major levator abnormalities in symptomatic patients with an underactive pelvic floor contraction. Int Urogynecol J 2010;21(7):861-867.

39. Lekskulchai O, Dietz HP. Is detrusor hypertrophy in women associated with voiding dysfunction? Aust N Z J Obstet Gynaecol 2009;49(6):653-656.

40. Deirmentzoglou S, Giannitsas K, Perimenis P, Petsas T, Athanasopoulos A. Correlation of ultrasound-estimated bladder weight to urodynamic diagnoses in women with lower urinary tract symptoms. Urology 2012;80(1):66-70.

41. Sheyn D, Ahmed Y, Azar N, El-Nashar S, Hijaz A, Mahajan S. Trans-abdominal ultrasound shear wave elastographyfor quantitative assessment of female bladder neck elasticity. Int Urogynecol J 2017;28(5):763-768.

42. Ergin G, Kibar Y, Ebiloglu T, et al. The role of urinary nerve growth factor for the diagnosis and assessment of the biofeedback success in children with dysfunctional voiding. J Pediatr Urol 2016;12(2):118 e111-116.

43. Chuang FC, Kuo HC. Correlation of bladder base elevation with pelvic floor hypertonicity in women with lower urinary tract symptoms. Neurourol Urodyn 2007;26(4):502-506.

44. Amarenco G, Raibaut P, Ismael SS, Rene-Corail P, Haab F. Evidence of occult dysautonomia in Fowler's syndrome: alteration of cardiovascular autonomic function tests in female patients presenting with urinary retention. BJU Int 2006;97(2):288-291.

45. Chang YC, Chuang LM. The role of oxidative stress in the pathogenesis of type 2 diabetes: from molecular mechanism to clinical implication. Am J Transl Res 2010;2(3):316-331.

46. Jiang YH, Kuo HC. Urothelial Barrier Deficits, Suburothelial Inflammation and Altered Sensory Protein Expression in Detrusor Underactivity. J Urol 2017;197(1):197-203.

47. le Feber J, van Asselt E, van Mastrigt R. Afferent bladder nerve activity in the rat: a mechanism for starting and stopping voiding contractions. Urol Res 2004;32(6):395-405.

48. Lin TL, Chen GD, Chen YC, Huang CN, Ng SC. Aging and recurrent urinary tract infections are associated with bladder dysfunction in type 2 diabetes. Taiwan J Obstet Gynecol 2012;51(3):381-386.

49. Smith PP. Aging and the underactive detrusor: a failure of activity or activation? Neurourol Urodyn 2010;29(3):408-412.

50. Dray A, Nunan L, Wire W. Central delta-opioid receptor interactions and the inhibition of reflex urinary bladder contractions in the rat. Br J Pharmacol 1985;85(3):717-726.

51. Durant PA, Yaksh TL. Drug effects on urinary bladder tone during spinal morphine-induced inhibition of the micturition reflex in unanesthetized rats. Anesthesiology 1988;68(3):325-334.

52. Rawal N, Mollefors K, Axelsson K, Lingardh G, Widman B. An experimental study of urodynamic effects of epidural morphine and of naloxone reversal. Anesth Analg 1983;62(7):641-647.

53. Petersen TK, Husted SE, Rybro L, Schurizek BA, Wernberg M. Urinary retention during i.m. and extradural morphine analgesia. Br J Anaesth 1982;54(11):1175-1178.

54. Dolin SJ, Cashman JN. Tolerability of acute postoperative pain management: nausea, vomiting, sedation, pruritus, and urinary retention. Evidence from published data. Br J Anaesth 2005;95(5):584-591.

55. Malinovsky JM, Le Normand L, Lepage JY, et al. The urodynamic effects of intravenous opioids and ketoprofen in humans. Anesth Analg 1998;87(2):456-461. 
56. Meyboom RH, Brodie-Meijer CC, Diemont WL, van Puijenbroek EP. Bladder dysfunction during the use of tramadol. Pharmacoepidemiol Drug Saf 1999;8 Suppl 1:S63-64.

57. Panicker JN, Game X, Khan S, et al. The possible role of opiates in women with chronic urinary retention: observations from a prospective clinical study. J Urol 2012;188(2):480-484.

58. Hoeritzauer I, Stone J, Fowler C, Elneil-Coker S, Carson A, Panicker J. Fowler's syndrome of urinary retention: A retrospective study of co-morbidity. Neurourol Urodyn 2016;35(5):601-603.

59. Everaert K, De Ridder D, Baert L, Oosterlinck W, Wyndaele JJ. Patient satisfaction and complications following sacral nerve stimulation for urinary retention, urge incontinence and perineal pain: a multicenter evaluation. Int Urogynecol J Pelvic Floor Dysfunct 2000;11(4):231235; discussion 236.

60. Marcelissen TA, Leong RK, Nieman FH, van Lankveld JJ, van Kerrebroeck PE, de Wachter SG. Psychological and psychiatric factors as predictors for success in sacral neuromodulation treatment. BJU Int 2011;108(11):1834-1838.

61. De Ridder D, Ost D, Bruyninckx F. The presence of Fowler's syndrome predicts successful longterm outcome of sacral nerve stimulation in women with urinary retention. Eur Urol 2007;51(1):229-233; discussion 233-224.

62. Spinelli M, Bertapelle $\mathrm{P}$, Cappellano $F$, et al. Chronic sacral neuromodulation in patients with lower urinary tract symptoms: results from a national register. J Urol 2001;166(2):541-545.

63. Kellogg N, American Academy of Pediatrics Committee on Child A, Neglect. The evaluation of sexual abuse in children. Pediatrics 2005;116(2):506-512.

64. Leserman J. Sexual abuse history: prevalence, health effects, mediators, and psychological treatment. Psychosom Med 2005;67(6):906-915.

65. Link CL, Lutfey KE, Steers WD, McKinlay JB. Is abuse causally related to urologic symptoms? Results from the Boston Area Community Health (BACH) Survey. Eur Urol 2007;52(2):397-406.

66. Klevan JL, De Jong AR. Urinary tract symptoms and urinary tract infection following sexual abuse. Am J Dis Child 1990;144(2):242-244.

67. Davila GW, Bernier F, Franco J, Kopka SL. Bladder dysfunction in sexual abuse survivors. J Urol 2003;170(2 Pt 1):476-479.

68. Beck JJ, Elzevier HW, Pelger RC, Putter H, Voorham-van der Zalm PJ. Multiple pelvic floor complaints are correlated with sexual abuse history. J Sex Med 2009;6(1):193-198.

69. Kessler TM, Fowler CJ. Sacral neuromodulation for urinary retention. Nat Clin Pract Urol 2008;5(12):657-666.

70. Kavia R, Dasgupta R, Critchley H, Fowler C, Griffiths D. A functional magnetic resonance imaging study of the effect of sacral neuromodulation on brain responses in women with Fowler's syndrome. BJU Int 2010;105(3):366-372.

71. Li X, Liao L, Chen G, Wang Z, Deng H. Involvement of opioid receptors in inhibition of bladder overactivity induced by sacral neuromodulation in pigs: A possible action mechanism. Neurourol Urodyn 2017;36(7):1742-1748.

72. Rademakers KL, Drossaerts JM, van Kerrebroeck PE, Oelke M, van Koeveringe GA. Prediction of sacral neuromodulation treatment success in men with impaired bladder emptying-time for a new diagnostic approach. Neurourol Urodyn 2017;36(3):808-810.

73. Hennessey DB, Hoag N, Gani J. Sacral neuromodulation for detrusor hyperactivity with impaired contractility. Neurourol Urodyn 2017.

74. Goh M, Diokno AC. Sacral neuromodulation for nonobstructive urinary retention--is success predictable? J Urol 2007;178(1):197-199; discussion 199.

75. Drossaerts J, Rademakers K, van Koeveringe G, Van Kerrebroeck P. The value of urodynamic tools to guide patient selection in sacral neuromodulation. World J Urol 2015;33(11):1889-1895. 
76. Faris AER, Gill BC, Pizarro-Berdichevsky J, et al. Impact of Age and Comorbidities on Use of Sacral Neuromodulation. J Urol 2017;198(1):161-166.

77. Weil EH, Ruiz-Cerda JL, Eerdmans PH, Janknegt RA, Van Kerrebroeck PE. Clinical results of sacral neuromodulation for chronic voiding dysfunction using unilateral sacral foramen electrodes. World J Urol 1998;16(5):313-321.

78. White WM, Mobley JD, 3rd, Doggweiler R, Dobmeyer-Dittrich C, Klein FA. Incidence and predictors of complications with sacral neuromodulation. Urology 2009;73(4):731-735.

79. Datta SN, Chaliha C, Singh A, et al. Sacral neurostimulation for urinary retention: 10 -year experience from one UK centre. BJU Int 2008;101(2):192-196.

80. Drossaerts J, Vrijens D, Leue C, Schilders I, Van Kerrebroeck P, van Koeveringe G. Screening for depression and anxiety in patients with storage or voiding dysfunction: A retrospective cohort study predicting outcome of sacral neuromodulation. Neurourol Urodyn 2016;35(8):1011-1016. 
